\title{
Preparation of $\mathrm{HCl}$ Gas Sorbent from Paper Sludge
}

\author{
Takaaki Wajima \\ Department of Urban Environment Systems, Chiba University, Chiba, Japan \\ Email: wajima@tu.chiba-u.ac.jp
}

How to cite this paper: Wajima, T. (2017) Preparation of $\mathrm{HCl}$ Gas Sorbent from $\mathrm{Pa}$ per Sludge. Natural Resources, 8, 291-299. https://doi.org/10.4236/nr.2017.84017

Received: February 20, 2017

Accepted: April 21, 2017

Published: April 25, 2017

Copyright $\odot 2017$ by author and Scientific Research Publishing Inc. This work is licensed under the Creative Commons Attribution International License (CC BY 4.0).

http://creativecommons.org/licenses/by/4.0/

\begin{abstract}
Paper sludge (PS) is generated as an industrial waste during the manufacture of recycled paper products, and amounts discharged globally are increasing annually. On the other hands, hydrogen chloride $(\mathrm{HCl})$ is an acidic pollutant that is present in the flue gases of most municipal and hazardous waste incinerators. In this study, the removal of hydrogen chloride gas using the product from paper sludge at high temperatures $\left(700^{\circ} \mathrm{C}\right)$ using a fixed-bed flowtype reactor was investigated. PS can be granulated with distilled water using granulators, and the particle shapes can be kept after calcination and alkali reaction. Calcined PS and the product after alkali reaction of calcined PS have amorphous phases and katoite $\left(\mathrm{Ca}_{3} \mathrm{Al}_{2}\left(\mathrm{SiO}_{4}\right)(\mathrm{OH})_{8}\right)$ phase, respectively, and both of these indicate $\mathrm{HCl}$ removal ability at high temperature $\left(700^{\circ} \mathrm{C}\right)$. The product from calcined PS via alkali reaction has higher $\mathrm{HCl}$ fixation ability (78 $\mathrm{mg} / \mathrm{g}$ ) than calcined PS. Removal experiments for $\mathrm{HCl}$ gas showed that the removal process followed pseudo-second-order kinetics rather than pseudofirst-order kinetics. These results suggested that the product particles with $\mathrm{HCl}$ gas removal ability at high temperature can be prepared from PS using calcination and alkali reaction.
\end{abstract}

\section{Keywords}

Paper Sludge, Hydrogen Chloride Gas, Granulation, Katoite, High Temperature

\section{Introduction}

During the manufacture of recycled paper, paper sludge is discharged as an industrial waste. Over 3 million tonnes of sludge are discharged per year in Japan, and approximately 8 and 2 million tonnes are discharged in the United States and the United Kingdom, respectively [1] [2] [3]. These amounts are increasing annually. The paper industry is of great environmental importance due to the quantity of paper sludge generated, and its disposal. Although a small part of 
paper sludge is used as a soil improver and fertilizer in agriculture [4] [5] [6] [7] [8], most of paper sludge is usually disposed of in open dumps or in landfills after incineration. Recently, reduction of available landfill space increasing costs of land disposal of waste in industrial countries necessitates other means for the disposal of waste paper sludge. An economically valuable solution to this problem should include utilization of the waste materials as new products for other applications rather than disposal in a landfill.

Combustion processes, especially municipal waste combustion and hazardous waste incineration, require in most cases the removal of air pollutants, especially hydrogen chloride $(\mathrm{HCl})$ gas [9] [10]. The high solubility and corrosive nature of $\mathrm{HCl}$ gas make it one of the most troublesome acidic gases even though it is not emitted into the environment in particularly large quantities. $\mathrm{HCl}$ must be removed from flue gases before the flue gases are emitted to the atmosphere. The combustion of municipal and hazardous waste is a major source of $\mathrm{HCl}$ to the environment. In recent years, a great deal of attention has been paid to the problem of reducing the level of atmospheric pollution caused by $\mathrm{HCl}$ gas. The present techniques for removing $\mathrm{HCl}$ gas use calcium hydroxide $\left(\mathrm{Ca}(\mathrm{OH})_{2}\right)$ and calcium carbonate $\left(\mathrm{CaCO}_{3}\right)$ at low temperatures (below $300^{\circ} \mathrm{C}$ ) because they are relatively simple, easy to operate, and have low capital costs [11] [12] [13]. However, these techniques may evolve polychlorinated dibenzo-p-dioxins (PCDDs) and dibenzo-frans (PCDFs) by de novo synthesis in the municipal waste incineration process [14], and cause hot corrosion of the body of the incinerator.

In this study, we attempted to prepare the materials with $\mathrm{HCl}$ removal ability at high temperature from paper sludge. In our previous study, katoite, one of the hydrogarnet group mineral, was synthesized from paper sludge ash using alkali reaction with $\mathrm{NaOH}$ [15]. Hydrogarnet $\left(\mathrm{Ca}_{3} \mathrm{Al}_{2}\left(\mathrm{SiO}_{4}\right)(\mathrm{OH})_{8}\right)$ is known as a major product of the hydration of calcium aluminate cements, and could be very useful for the fixation of hydrogen chloride gas at high temperatures [16] [17]. The aim of this study was to develop a new method for the removal of the $\mathrm{HCl}$ gas present in the gas burning at high temperatures using the particle including hydrogarnet synthesized from paper sludge as a starting material.

\section{Experimental}

\subsection{Sample}

Paper sludge (PS) from a paper company in Japan was used as the starting material. The PS was dried at $80^{\circ} \mathrm{C}$ overnight, and sieved for particle size less than $250 \mu \mathrm{m}$. The chemical composition of the PS is listed in Table 1. The PS contained $4.3 \%$ moisture, organic components such as cellulose fibers $(29.0 \%)$, and inorganic components (66.7\%), predominantly $\mathrm{CaO}(29.7 \%), \mathrm{SiO}_{2}(15.5 \%)$, and $\mathrm{Al}_{2} \mathrm{O}_{3}$ (15.6\%). The moisture and organic contents in the PS were determined by differential thermal analysis (DTA)/thermogravimetry (TG) (TG8120, Rigaku, Japan) in the temperature range $20^{\circ} \mathrm{C}-1000^{\circ} \mathrm{C}$ at a heating rate of $10^{\circ} \mathrm{C} / \mathrm{min}$ in flowing air. The inorganic elements in the PS were determined by X-ray fluorescence (XRF) (Primini, Rigaku, Japan). 
Table 1. Chemical composition of paper sludge (wt.\%).

\begin{tabular}{|c|c|c|c|c|c|c|c|c|c|}
\hline \multirow{2}{*}{ Moisture } & \multirow{2}{*}{ Organic Content } & \multicolumn{8}{|c|}{ Inorganic Content } \\
\hline & & $\mathrm{CaO}$ & $\mathrm{SiO}_{2}$ & $\mathrm{Al}_{2} \mathrm{O}_{3}$ & $\mathrm{MgO}$ & $\mathrm{Fe}_{2} \mathrm{O}_{3}$ & $\mathrm{Cl}$ & $\mathrm{SO}_{3}$ & $\mathrm{P}_{2} \mathrm{O}_{5}$ \\
\hline 4.3 & 29.0 & 29.7 & 15.5 & 15.6 & 4.1 & 0.7 & 0.1 & 0.4 & 0.2 \\
\hline
\end{tabular}

\subsection{Granulation and Calcination}

In this study, two types of granule particles were prepared from paper sludge using a pan granular (DPZ-01R, as one, Japan) and granule maker (KAR-75, Tsutsui Rigaku kikai, Japan), respectively.

A pan granular with a diameter of $300 \mathrm{~mm}$ and depth of $120 \mathrm{~mm}$ was used for granulation of paper sludge. The pan speed was fixed at $50 \mathrm{rpm}$ and pan angle at $45^{\circ}$. Initially, distilled water was sprayed using a hand held sprayer on the granulator surface and powder PS were added to form a wet bed. 10 grams of powder PS was used, and addition of distilled water to rotation pan granulator was used as they helped in formation of granules. After the granulation process, the samples were first dried in a drying oven overnight, and then the granulated particles within the range between $2 \mathrm{~mm}$ and $4 \mathrm{~mm}$ were selected by the sieving process.

A granule maker has the cylindrical basket with the diameter of $75 \mathrm{~mm}$ and its cylindrical inner wall has the $1 \mathrm{~mm}$ holes on the surface. The PS powder was mixed with distilled water in the basket by three blade impeller, and then the mixture was squeezed out of the basket to form the cylindrical PS. These cylindrical PS was dried in a drying oven overnight to prepare the cylindrical particles.

The obtained PS particles were calcined at $800^{\circ} \mathrm{C}$ for $1 \mathrm{~h}$ in an electric furnace under air atmosphere, and then cooled to room temperature to obtain the calcined sample.

\subsection{Synthesis}

Alkali conversion was performed in $50 \mathrm{~mL}$ Teflon-lined autoclave. One gram of the PS granules were added into $10 \mathrm{~mL}$ of $3 \mathrm{M} \mathrm{NaOH}$ solution in autoclave, and then heated at $100^{\circ} \mathrm{C}$ for $8 \mathrm{~h}$ in an electric furnace. After reaction, the solid product was separated from the solution by filtration, washed with distilled water and dried at $60^{\circ} \mathrm{C}$ overnight in a drying oven. The crystalline phases in each sample were identified by powder X-ray diffraction using monochromated $\mathrm{CuKa}$ radiation (XRD) (Ultima IV, Rigaku, Japan).

\subsection{HCl Gas Removal}

The experiments in which $\mathrm{HCl}$ gas was fixed using the samples at high temperatures were performed in a vertical reactor, shown schematically in Figure 1. The reactor was a fused silica tube $(17 \mathrm{~mm}$ i.d., $1 \mathrm{~m}$ long). The reactor was surrounded by an electric furnace to control its temperature. The sample was placed in the reactor, then $\mathrm{N}_{2}$ was passed through the reactor at $1 \mathrm{~L} / \mathrm{min}$ (the volume 


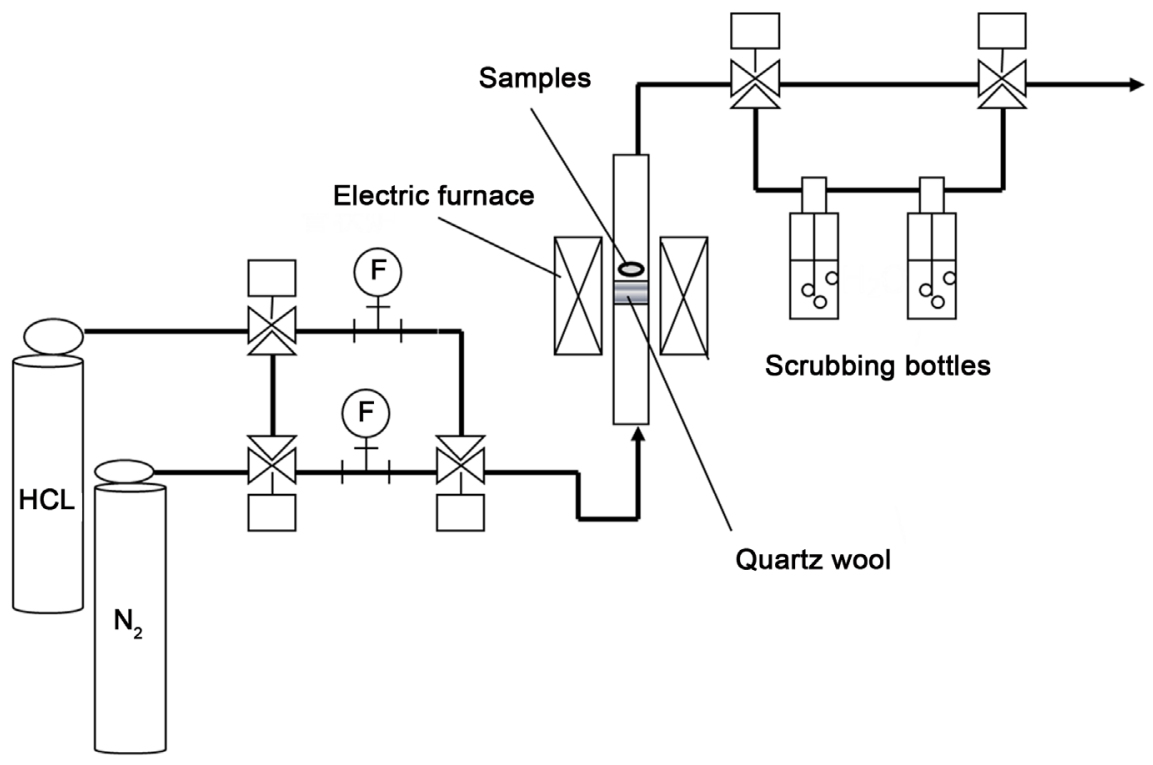

Figure 1. Experimental apparatus used in this study.

being measured at NTP) to replace the atmosphere in the reactor with $\mathrm{N}_{2}$. The reactor was then heated to $700^{\circ} \mathrm{C}$ with $\mathrm{N}_{2}$ flowing through it at $1 \mathrm{~L} / \mathrm{min}$. Once the required temperature was reached, the reaction gas (1000-ppmv $\mathrm{HCl}$ in $\mathrm{N}_{2}$ ) was fed at $500 \mathrm{~mL} / \mathrm{min}$ into the fixed-bed reactor. An $\mathrm{HCl}$ concentration of 1000 ppmv is similar to the average concentration in incinerator exhaust gas in Japan. Each experiment was ended when the outlet $\mathrm{HCl}$ concentration reached 1000 ppmv. The gas exiting the reactor was periodically passed through distilled water in scrubbing bottles for $5 \mathrm{~min}$, which was enough time for all of the $\mathrm{HCl}$ in the gas to be dissolved. The $\mathrm{Cl}^{-}$concentrations in the solution from the scrubbing bottle samples were determined using an ion meter (TiN-5102; Toko Instruments, Tokyo, Japan) to allow the amount of $\mathrm{Cl}^{-}$fixed by the samples to be determined. The $\mathrm{HCl}$ feed gas was stopped at the end of the experiment, and $\mathrm{N}_{2}$ was fed into the reactor until the reactor had cooled to room temperature. The solid sample in the reactor was then collected. The $\mathrm{Cl}^{-}$content of each solid sample that had been used in an $\mathrm{HCl}$ removal experiment was determined. A $0.1 \mathrm{~g}$ aliquot of a sample was added to $10 \mathrm{~mL}$ of $0.1 \mathrm{M} \mathrm{HNO}_{3}$ solution in a 50$\mathrm{mL}$ centrifuge tube, then the tube was shaken using a reciprocal shaker for $6 \mathrm{~h}$. The tube was then centrifuged for $10 \mathrm{~min}$, and the $\mathrm{Cl}^{-}$concentration in the supernatant was determined to allow the $\mathrm{Cl}^{-}$fixed content of the solid sample to be calculated.

\section{Results and Discussion}

Figure 2 shows the photos of (a) raw PS, (b) granuled PS, and (c) cylindrical PS. Two types of granules, granulated PS ( $\$ 2-4 \mathrm{~mm}$ ) (Figure 2(b)) and cylindrical PS ( $\phi 1 \mathrm{~mm}$ ) (Figure 2(c)) can be prepared from fine powdered PS (Figure 2(a)) using distilled water, which means that the granulation of PS is possible without chemical binders. 

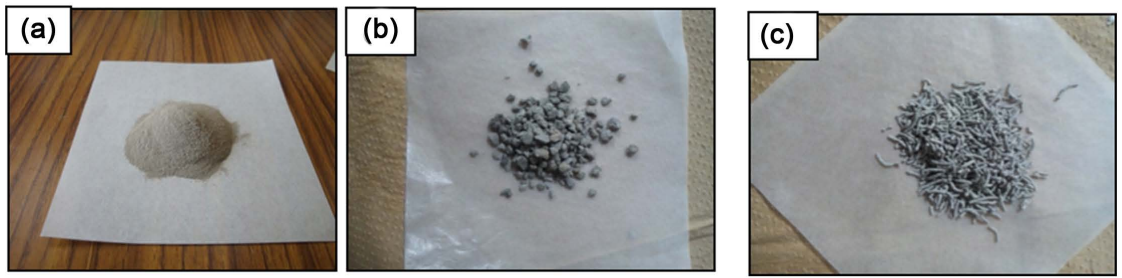

Figure 2. Photos of (a) raw paper sludge; (b) granuled PS and (c) cylindrical PS.

Figure 3 shows the photos of (a) calcined granuled PS, (b) calcined cyrindrical PS, (c) the product from calcined granuled PS, and (d) the product from calcined cylindrical PS. Calcined samples keep the granulation forms with white color and their weight decrease due to the burning the organic content in PS. Furthermore, the products after alkali reaction keep the granulation forms with white color and become hard.

Figure 4 shows the X-ray diffraction patterns of (a) raw PS, (b) calcined PS, and (c) the product from calcined PS. It is noted that the XRD patterns for granule PS and cylindrical PS indicate almost same. Raw PS mainly composed of organic cellulose (with relatively broad peaks owing to the low crystallinity of the fibers around $\left.2 \theta=20^{\circ}\right)$ and inorganic minerals, calcite $\left(\mathrm{CaCO}_{3}\right)$, kaolinite $\left(\mathrm{Al}_{2} \mathrm{Si}_{2} \mathrm{O}_{5}(\mathrm{OH})_{4}\right)$ and talc $\left(\mathrm{Mg}_{3} \mathrm{Si}_{4} \mathrm{O}_{10}(\mathrm{OH})_{2}\right)$ (the filler and/or coating components of paper) (Figure 4(a)). After calcination, the peaks of talc remained, those of kaolinite and calcite disappeared and those of lime appeared due to the decarbonation of calcite and the formation of amorphous $\mathrm{CaO}-\mathrm{Al}_{2} \mathrm{O}_{3}-\mathrm{SiO}_{2}$ (CAS) [18] [19] (Figure 4(b)). Finally, the product mainly composed of katoite $\left(\mathrm{Ca}_{3} \mathrm{Al}_{2}\left(\mathrm{SiO}_{4}\right)(\mathrm{OH})_{8}\right)$, which belongs to hydrogarnet group known as the materials with $\mathrm{HCl}$ removal ability (Figure $4(\mathrm{c})$ ).

The $\mathrm{HCl}$ removal tests using calcined granule PS and the product were carried out. The amounts of $\mathrm{Cl}^{-}$fixed by calcined PS and the product at $700^{\circ} \mathrm{C}$ as a function of the reaction time are shown in Figure 5. Both calcined PS and the product have the $\mathrm{HCl}$ removal ability. The $\mathrm{HCl}$ removal rate of the product was high in the first $60 \mathrm{~min}$, then lower until equilibrium was reached, while that of calcined PS was in the first $40 \mathrm{~min}$, then be almost constant. The total amount of fixed $\mathrm{Cl}^{-}$content in the product is $78 \mathrm{mg} / \mathrm{g}$, which is higher than that in calcined PS.

The experimental kinetic data were fitted using a pseudo-first-order kinetic model [20] and a pseudo-second-order kinetic model [21], shown in (1) and (2), respectively,

$$
\begin{gathered}
\ln \left(q_{e}-q_{t}\right)=\ln q_{e}-k_{1} t \\
\frac{t}{q_{t}}=\frac{1}{k_{2} \mathrm{n} q_{e}^{2}}+\frac{1}{q_{e}} t
\end{gathered}
$$

where $k_{1}\left(\mathrm{~min}^{-1}\right)$ and $k_{2}\left(\mathrm{~min}^{-1}\right)$ are the first order and second order rate constants, respectively. Equations (1) and (2) were applied for times between $t=0$ and $t=t_{e}$ (the equilibration time, which was usually different for the different systems). $q_{e}(\mathrm{mg} / \mathrm{g})$ is the amount of $\mathrm{Cl}^{-}$fixed at $t_{e}$. The values of $k_{1}, k_{2}, R^{2}$ (the linear correlation coefficient), and $q_{e}\left(\right.$ i.e., $q_{e, 1}$ and $q_{e, 2}$ ) are shown in Table 2. 

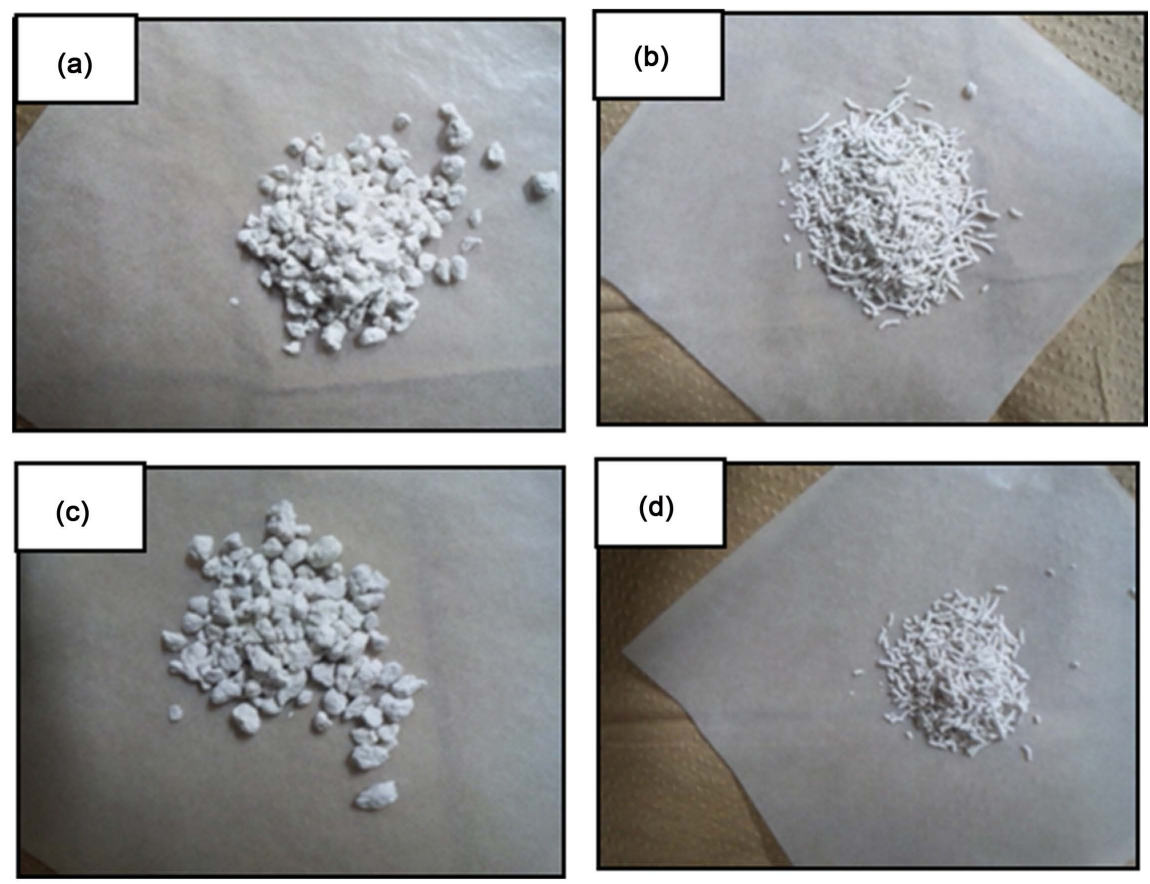

Figure 3. Photos of (a) calcined granuled PS; (b) calcined cylindrical PS; (c) the product from calcined granuled PS; and (d) the product from calcined cylindrical PS.

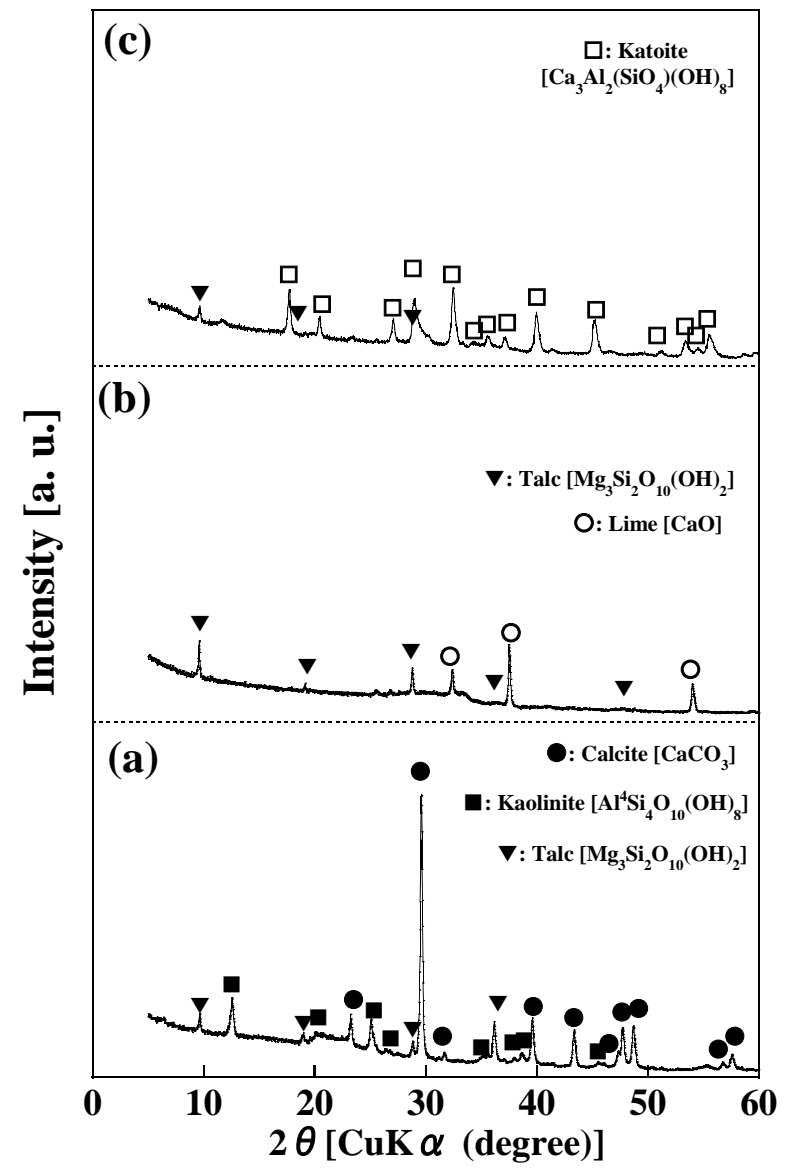

Figure 4. X-ray diffraction patterns of (a) raw PS; (b) calcined PS; and (c) the product from calcined PS. 


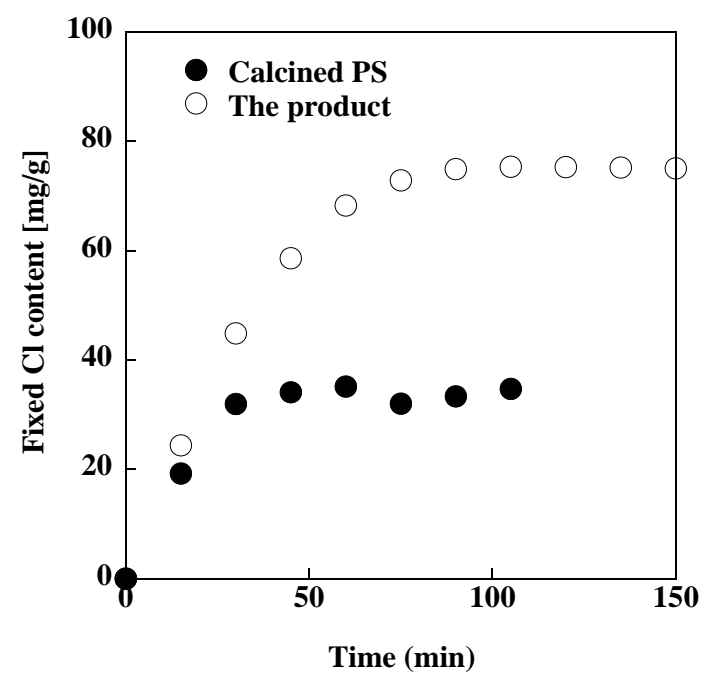

Figure 5. Fixed $\mathrm{Cl}$ contents in the samples during the $\mathrm{HCl}$ removal test.

Table 2. Parameters for the fixation of $\mathrm{HCl}$ gas by calcined PS and the product.

\begin{tabular}{ccccccc}
\hline \multirow{2}{*}{ Sample } & \multicolumn{2}{c}{ Pseudo-first-order kinetics model } & \multicolumn{3}{c}{ Pseudo-second-order kinetics model } \\
\cline { 2 - 6 } & $q_{e, 1}(\mathrm{mg} / \mathrm{g})$ & $k_{1}(1 / \mathrm{min})$ & $R^{2}$ & $q_{e, 2}(\mathrm{mg} / \mathrm{g})$ & $k_{2}(1 / \mathrm{min})$ & $R^{2}$ \\
\hline Calcined PS & 10.5 & 0.014 & 0.425 & 37.3 & 3.3 & 0.984 \\
The product & 60.7 & 0.0079 & 0.759 & 99.0 & 0.3 & 0.973 \\
\hline
\end{tabular}

The $R^{2}$ values showed that, regardless of the temperature, the experimental data fitted the pseudo-second-order model much better than the pseudo-firstorder model, indicating that the fixation process was second order.

\section{Conclusion}

We attempted to prepare the particles with $\mathrm{HCl}$ removal ability from PS. PS can be granulated with distilled water using a pan granular and granule maker, and the shapes of particles were unchanged by calcination and alkali reaction. Calcined PS and the product from calcined PS via alkali reaction have amorphous phases and katoite, respectively, and indicate the removal ability for $\mathrm{HCl}$ gas at $700^{\circ} \mathrm{C}$. The product has higher removal ability for $\mathrm{HCl}$ gas than calcined PS. The removal reaction kinetics is found to fit the pseudo-second-order kinetics model better than the pseudo-first-kinetics model. Therefore, PS can be granulated simply using only water, and the product particles with $\mathrm{HCl}$ gas removal ability at high temperature can be prepared from PS by calcination and alkali reaction.

\section{References}

[1] Barton, R.G., Seeker, W.R. and Bostian, H. E. (1991) The Behavior of Metals in Municipal Sludge Incinerator. Transactions of the Institute of Chemical Engineers, 69, 29-36.

[2] Tebbutt, T.H.Y. (1995) Incineration of Waste Water Sludges. Proceedings of the Institution of Civil Engineers. Water, Maritime and Energy, 112, 39-47. http://dx.doi.org/10.1680/iwtme.1995.27292 
[3] Ishimoto, H., Origuchi, T. and Yasuda, M. (2000) Use of Papermaking Sludge as New Material. Journal of Materials in Civil Engineering, 12, 310-313. http://dx.doi.org/10.1061/(ASCE)0899-1561(2000)12:4(310)

[4] Henry, C.L. (1991) Nitrogen Dynamics of Pulp and Paper Sludge Amendment to Forest Soils. Water Science and Technology, 24, 417-425.

[5] Tripepi, R.R., Zhang, X. and Campbell, A.G. (1996) Use of Raw and Composted Paper Sludge as a Soil Additive or Mulch for Cottonwood Plants. Compost Science and Utilization, 4, 26-36. http://dx.doi.org/10.1080/1065657X.1996.10701827

[6] Dell'Abate, M.T., Benedetti, A. and Sequi, P. (2000) Thermal Method of Organic Matter Maturation Monitoring during a Composting Process. Journal of Thermal Analysis and Calorimetry, 61, 389-396. http://dx.doi.org/10.1023/A:1010157115211

[7] Barriga, S., Méndez, A., Cámara, J., Guerrero, F. and Gascó, G. (2010) Agricultural Valorization of De-Inking Paper Sludge as Organic Amendment in Different Soils. Journal of Thermal Analysis and Calorimetry, 99, 981-986. http://dx.doi.org/10.1007/s10973-010-0692-1

[8] Méndez, A., Barriga, S., Guerrero, F. and Gascó, G. (2011) Thermal Analysis of Growing Media obtained from Mixtures of Paper Mill Waste Materials and Sewage Sludge. Journal of Thermal Analysis and Calorimetry, 104, 213-221. http://dx.doi.org/10.1007/s10973-010-1227-5

[9] Fujita, S., Suzuki, K. and Shibasaki, Y. (2002) The Mild Hydrothermal Synthesis of Hydrogrossular from Coal Ash. Journal of Material Cycles and Waste Management, 4, 41-45.

[10] Fujita, S., Suzuki, K., Ohkawa, M., Shibasaki, Y. and Mori, T. (2001) Reaction of Hydrogrossular with Hydrogen Chloride Gas at High Temperature. Chemistry of Materials, 13, 2523-2527. http://dx.doi.org/10.1021/cm000863r

[11] Daoudi, M. and Walters, J.K. (1991) The Reaction of HCl Gas with Calcined Commercial Limestone Particles: The Effect of Particle Size. Chemical Engineering Journal, 47, 11-16.

[12] Mura, G. and Lallai, A. (1992) On the Kinetics of Dry Reaction between Calcium Oxide and Gas Hydrochloric Acid. Chemical Engineering Science, 47, 2407-2411. http://dx.doi.org/10.1016/0009-2509(92)87068-2

[13] Weinell, C.E., Jensen, P.I., Dam-Johansen, K. and Livbjerg, H. (1992) Hydrogen Chloride Reaction with Lime and Limestone: Kinetics and Sorption Capacity. Industrial and Engineering Chemistry Research, 31, 164-171. http://dx.doi.org/10.1021/ie00001a023

[14] Stieglitz, L., Zwick, G., Beck, J., Bautz, H. and Roth, W. (1989) Carbonaceous Particles in Fly Ash-A Source for the De-Novo-Synthesis of Organochloro Compounds. Chemosphere, 19, 283-290.

[15] Wajima, T. and Munakata, K. (2011) Material Conversion from Paper Sludge Ash in $\mathrm{NaOH}$ Solution to Synthesize Adsorbent for Removal of $\mathrm{Pb}^{2+}, \mathrm{NH}_{4}^{+}$and $\mathrm{PO}_{4}^{3-}$ from Aqueous Solution. Journal of Environmental Sciences, 23, 718-724.

[16] Fujita, S., Suzuki, K., Shibasaki, Y. and Mori, T. (2002) Synthesis of Hydrogarnet from Molten Slag and its Hudrogen Chloride Fixation Performance at High Temperature. Journal of Material Cycles and Waste Management, 4, 70-76. http://dx.doi.org/10.1007/s10163-001-0059-6

[17] Fujita, S., Ogawa, N. Yamasaki, T., Fukuda, T., Sataka, S., Suzuki, K., Shibasaki, Y. and Mori, T. (2004) A New Sorbent, Hydorgarnet, with Purging $\mathrm{HCl}$ Gas at High Temperature. Chemical Engineering Journal, 102, 99-104. http://dx.doi.org/10.1016/j.cej.2004.01.035 
[18] Wajima, T. and Rakovan, J.F. (2013) Removal Behavior of Phosphate from Aqueous Solution by Calcined Paper Sludge. Colloids and Surfaces A, 435, 132-138.

[19] Wajima, T. and Rakovan, J.F. (2013) Removal of Fluoride Ions using Calcined Paper Sludge. Journal of Thermal Analysis and Calorimetry, 113, 1027-1035. http://dx.doi.org/10.1007/s10973-012-2897-y

[20] Ho, Y.S. (2004) Citation Review of Lagergren Kinetic Rate Equation on Adsorption Reactions. Scientometrics, 59, 171-177. http://dx.doi.org/10.1023/B:SCIE.0000013305.99473.cf

[21] Ho, Y.S. and McKey, G. (1999) Pseudo-Second Order Model for Sorption Processes. Process Biochemistry, 34, 451-465.

http://dx.doi.org/10.1016/S0032-9592(98)00112-5

Submit or recommend next manuscript to SCIRP and we will provide best service for you:

Accepting pre-submission inquiries through Email, Facebook, LinkedIn, Twitter, etc. A wide selection of journals (inclusive of 9 subjects, more than 200 journals) Providing 24-hour high-quality service User-friendly online submission system Fair and swift peer-review system Efficient typesetting and proofreading procedure Display of the result of downloads and visits, as well as the number of cited articles Maximum dissemination of your research work

Submit your manuscript at: http://papersubmission.scirp.org/

Or contact nr@scirp.org 